\title{
A STUDY ON EMOTIONAL INTELLIGENCE OF SECONDARY SCHOOL STUDENTS WITH SPECIAL REFERENCE TO KAMRUP (M) DISTRICT OF ASSAM
}

\author{
Deepshikha Bharadwaz* \\ Assistant Professor, Department of Education, Province College, \\ Tetelia, Guwahati, Assam, India \\ Rabbul Hussain \\ Assistant Professor, Department of Education, Province College, \\ Tetelia, Guwahati, Assam, India \\ *Corresponding Author
}

\begin{abstract}
Emotional intelligence is considered as an important ability for a well balance life. In human life, it has a great importance. It always helps people to manage their own emotion, aware about it as well as others too. The present study is an attempt to study about emotional intelligence of secondary school students of Kamrup (M) district. Here descriptive survey method is used. The population of this study consists of all the students studying in secondary school of Guwahati city of Kamrup (M) District. Out of these, 156 students have been selected from 4 secondary schools, where 78 numbers of girls and 78 numbers of boys are there. The findings revealed that most of the secondary school students fall under average level of emotional intelligence.
\end{abstract}

Key words: Ability, Emotional Intelligence, Emotion, People, Secondary School

Cite this Article: Deepshikha Bharadwaz and Rabbul Hussain, A Study on Emotional Intelligence of Secondary School Students with Special Reference to Kamrup (M) District of Assam, International Journal of Management, 11(12), 2020, pp 1580-1588.

http://iaeme.com/Home/issue/IJM?Volume $=11 \&$ Issue $=12$

\section{INTRODUCTION}

Emotion is meant as feelings, which directs behavior, in the same way intelligence always denotes some concepts like 'ability' capacity as well as power of mind. Emotional intelligence is a term refers cooperative combination of emotion and intelligence. Emotional 
intelligence is a concept which always deals with the capacity, power to handle, control, as well as express one's emotions, and others too.

According to John Mayer, "The ability to monitor one's own and other people's emotions, to discriminate between different emotions and take them appropriately, and to use emotional information to guide thinking and behavior"

Emotional intelligence is totally a new concept of never related with cognitive intelligence. While cognitive intelligence deals with some concepts like ability, understanding, decision making capacity, problem solving capacity; emotional intelligence is complex concept, it never always go hand in hand with this kind of skill. Especially if we hope to succeed in life, this is where emotional intelligence becomes important. Simply, emotional intelligence is the ability to recognize one's emotion, understand others and realize how one's emotions affect people around him. It always includes our perception towards others, how we understand others and manage our relationships.

Emotional intelligence always can be improved. It always helps person to develop their soft skill. As our society evolves, all are becoming more sophisticated, efficient in a number of ways; more educated and smarter too, it is the emotional intelligence which motivates us and also helps us to work more co-operative with others.

Secondary stage of education is one of the most significant stage because in this stage only they prepare themselves as a knowledgeable person by getting basic education as well as it is also significant from the point of view the adolescence period, which is said as most crucial period of human life comes under this secondary stage. The students of secondary education are mostly adolescent, where they experience new things, most importantly emotions. In this stage, both boys and girls experience various kinds of emotions, and sometimes they cannot differentiate between them. In this phase they generally become more aware of their own feelings and the feelings of others, but these perceptions may still be tenuous. Adolescent emotional development is often characterized by rapidly fluctuating emotions; by the developmental nature they generally do not have proper control over their emotions. These things made a great influence on their studies. Emotional intelligence has a great impact of one's academic achievement. Because it always related with one's emotional management, motive, stress management capacity, self awareness, confidence, social management skill, which has significant combined impact on academic performance. Simply we can say that emotional intelligence incorporates the important aspects of interpersonal and intrapersonal relationships, adaptability, moods, which have a profound effect on the academic performance of students.

\section{REVIEW OF RELATED LITERATURE}

Some studies related with emotional intelligence of individual or students are mentioned in below-

- Farooq (2003) has studied about the effect of emotional intelligence on academic performance of adolescent students for which he selected 246 samples; study revealed that students with high level of emotional intelligence perform well combatively with that of the students having low level of emotional intelligence.

- Parkers and others (2005) investigated the impact of emotional intelligence on the successful transition level. The study result revealed that academically successful students had higher level of emotional and social competencies.

- Michael Ewela Ebinagbome and Dr. Tsmail Nizam (2016) conducted a study on "The impact of Emotional Intelligence on student's Academic performance: A study on Malaysian Tertiary Institution". It was carried out with the aim of examining the 
impact of emotional intelligence on students' academic performance of information technology and business management students. For this study he selected some independent variable of empathy and motivation has strong influence on academic performance of students.

- Antima Dwivedi and S.H. Qasion (2017) studied about Emotional Intelligence of Secondary level teachers. The objective of the study was to measure the emotional intelligence of the secondary school teachers of CBSC and UP Board Allahabad city. From this study they had found that male and female are different in emotional intelligence and teachers of both boards are different in emotional intelligence.

\section{SIGNIFICANT OF THE STUDY}

Emotional intelligence (EI) has recently emerged as one of the psychological construct. It always stands as a subject of protection of educational and occupational criteria. Most of the researcher found that we can strengthen our Emotional Intelligence. Today it is now conceded as a part of social intelligence. Emotional Intelligence is always related with emotions. It is an ability of managing ones' own emotions, aware about it as well as others too.

To be a successful in ones' own life, people should have this ability which always related to one's own self concept, motive as well as confident etc. From the students life people should give importance on it which is definitely recognized as one of the key factor of success.

The investigator consulted the different research done in the area of emotional intelligence of secondary school students of Kamrup (M) district and hardly found any significant study related to it. This research brings into light of new facts in this specific research area.

\section{OBJECTIVES OF THE STUDY}

Following objectives are formulated for the present study:

- To study the level of emotional intelligence of secondary school students.

- To compare the emotional intelligence of secondary school students with respect to their gender.

\section{HYPOTHESIS OF THE STUDY}

Keeping in view the objectives of the study, following hypotheses is formulated:

There is no significant difference between boys and girls studying in secondary schools as far as their Emotional Intelligence are concerned.

\section{OPERATIONAL DEFINITIONS}

- Ability- possession of the means or skill to do something.

- Emotional Intelligence- The capacity to be aware of, control and express one's emotions and to handle interpersonal relationship judiciously and empathically.

- Emotion- A strong feeling deriving from one's circumstances mood or relationships with others.

- People- Plurality of persons considered as a whole.

- Secondary School- An organization that provides secondary education. 


\section{METHODOLOGY}

Research Method: The present study was designed to study the emotional intelligence of secondary school students. For the present study "Descriptive Study Method" is used.

Population and Sample: The population of the study consists of all the students studying in Secondary Schools of Guwahati, Kamrup (M) district, Assam. For the study total 156 students have been selected from the 4 schools by applying simple random sampling method. Out of 156 samples 78Boys and 78 Girls are selected.

Table 1 Sample of study from the different secondary schools in Kamrup (M) district

\begin{tabular}{|l|c|c|c|}
\hline \multicolumn{1}{|c|}{ Name of the institutions } & $\begin{array}{c}\text { No. of } \\
\text { Boys }\end{array}$ & $\begin{array}{c}\text { No. of } \\
\text { Girls }\end{array}$ & Total \\
\hline Cotton Collegiate Govt. H.S. School & 25 & 29 & 54 \\
\hline Kamrup Academy Higher Secondary School & 33 & 29 & 62 \\
\hline T.C. Govt. Girls H.S. \& M.P. School & 0 & 20 & 20 \\
\hline Gopal Boro Government Higher Secondary School & 10 & 10 & 20 \\
\hline Grand Total & 78 & 78 & 156 \\
\hline
\end{tabular}

\section{Research Tool}

For this study Emotional Intelligence Inventory developed and standardized by S.K. Mangal and Shubhra Mangal is used. It has been designed for use with Hindi \& English knowing 16+ years age of school, college \& university students for the measurement of their Emotional Intelligence (total as well as separately) in respect of four areas namely, intra-personal awareness (knowing about one's own emotion), Inter-personal Awareness (knowing about others emotion), Intra-Personal management (Managing one's own emotion), Inter-Personal Management (Managing other's emotion) respectively. In this inventory there are 100 items, 25 each from the four areas to be answered as YES or NO.

\section{Statistical Support}

The data are mainly analysed in terms of percentage, Mean, Median, Standard deviation, Skewness, Kurtosis and t-test.

\section{Delimitation of the Study}

The present study is delimited to the students of only 4 secondary schools in Guwahati city i.e. Cotton Collegiate Government H.S. School, Kamrup Academy Higher Secondary School, T.C. Government Girls H.S. and M.P School, Gopal Boro Government Higher Secondary School of Kamrup (M) district, Assam.

\section{ANALYSIS AND INTERPRETATION}

The collected data for the present study are analyzed below: (According to the objectives)

\section{Objective: 1}

In order to study the level of emotional intelligence of secondary school students of Kamrup (M) district, considering the areas of emotional intelligence (Intra personal awareness, Inter personal awareness, Intra personal management, Inter personal management), the researcher found out mean, median, standard deviation, skewness and kurtosis. 
Table 2 Level of Emotional Intelligence of secondary students of Kamrup(M) district of Assam.

\begin{tabular}{|l|c|c|c|c|c|}
\hline \multicolumn{1}{|c|}{ Areas } & Mean & Median & SD & Sk & Ku \\
\hline $\begin{array}{l}\text { Emotional Intelligence Inventory } \\
\text { (Full scale) }\end{array}$ & 58.25 & 60.50 & 12.12 & -0.556 & 0.243 \\
\hline Intra personal Awareness & 14.26 & 14.25 & 3.51 & 0.008 & 0.277 \\
\hline Inter personal Awareness & 14.57 & 14.78 & 3.53 & -0.178 & 0.207 \\
\hline Intra personal Management & 14.67 & 14.80 & 4.24 & -0.091 & 0.286 \\
\hline Inter personal Management & 14.86 & 14.95 & 5.16 & -0.052 & 0.285 \\
\hline
\end{tabular}

From the table: 2 , it is observed that Mean, Median and SD are 58.25, 60.50, and 12.12 respectively. The distribution of Emotional Intelligence score of secondary students of Kamrup (M) district of Assam is negatively skewed or skewed toward the left i.e. scores are massed at the high end of the scale and are spread out more gradually towards the low end or the left. The value of kurtosis of Emotional Intelligence of secondary school students of Kamrup (M) district of Assam is 0.243 , less than 0.263. It means the distribution is leptokurtic.

The distribution of Emotional Intelligence (Intra personal awareness) scores of secondary students is positively skewed, scores are spread out more gradually towards the right and as they are massed at the high end of the scale. The value of Kurtosis is 0.277 which is greater than 0.263. It indicates that the distribution of the scores is platykurtic. The Mean, Md and SD is $14.26,14.25$, and 3.51 respectively.

The distribution of Emotional Intelligence (Inter Personal awareness) scores of secondary students is negatively skewed; scores are massed at the right end (high) and are spread out more gradually towards law end or the left. Mean, Md and SD is 14.57, 14.78 and 3.53 respectively. The kurtosis value is 0.207 which is less than 0.263 , shows that the distribution of scores is leptokurtic.

In the distribution of Emotional Intelligence (Intra personal Management) scores of secondary students is negatively skewed or skewed to the left, when scores are massed at the high end of the scale the value of Kurtosis is 0.286 which is greater than 0.263 , it indicates the distribution of the scores is platykurtic. The Mean, Median and SD are 14.67, 14.80, and 4.24 respectively.

The distribution of emotional intelligence (Inter personal Management) the Mean, Median and SD is $14.86,14.95,5.16$ respectively. The distribution is negatively skewed or to the left, i.e., scores are massed at the high end of the scale and are spread out more gradually towards the low. The value of kurtosis is 0.285 which is greater than 0.263 , it means the distribution is platykurtic.

Table 3 Categorization of secondary school students as a whole (Percentage)

\begin{tabular}{|l|c|c|c|c|c|}
\hline & $\begin{array}{c}\text { Very } \\
\text { Good }\end{array}$ & Good & Average & Poor & $\begin{array}{c}\text { Very } \\
\text { Poor }\end{array}$ \\
\hline Total sample & 1 & 5 & 69 & 53 & 28 \\
\hline Percentage & $0.64 \%$ & $3.20 \%$ & $44.25 \%$ & $33.99 \%$ & $17.94 \%$ \\
\hline
\end{tabular}

Table 3, depicts that only $0.64 \%$ secondary school students have very good level of emotional intelligence, $3.20 \%$ students have good level of emotional intelligence, $44.23 \%$ of secondary school students are found to have average level of emotional intelligence, $33.99 \%$ and $17.94 \%$ of students have Poor and very poor level of emotional intelligence respectively. 


\section{Graphical Representation of Table-3}

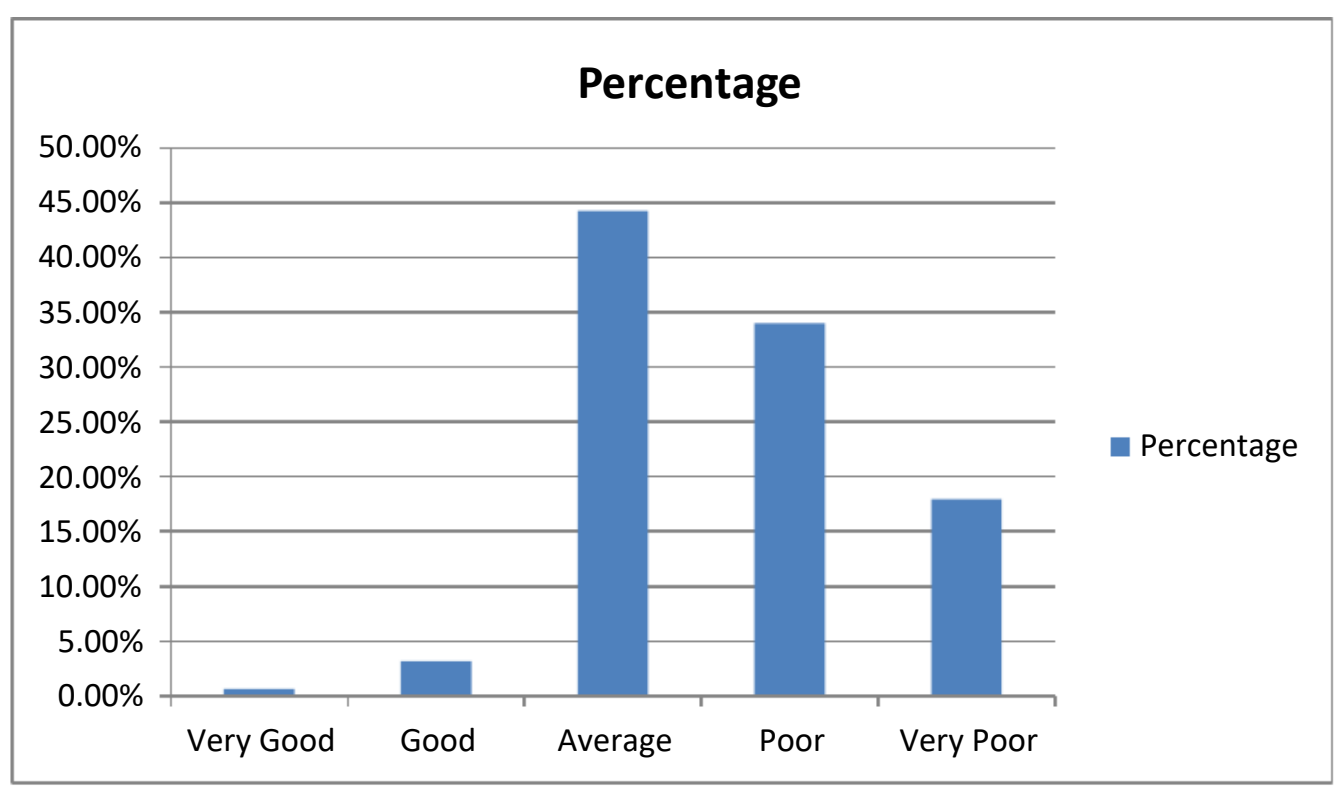

Figure 1

In order to determine the level of emotional intelligence of boys, the researcher administered the EII on 78 boys, after that she had calculated Mean, Median, SD, Skewness and Kurtosis.

Table 4 Level of Emotional Intelligence of boys

\begin{tabular}{|l|c|c|c|c|c|}
\hline \multicolumn{1}{|c|}{ Areas } & Mean & Median & SD & Sk & Ku \\
\hline $\begin{array}{l}\text { Emotional Intelligence Inventory } \\
\text { (Full Scale) }\end{array}$ & 55.58 & 60.08 & 13.46 & -1.00 & 0.311 \\
\hline Intra Personal Awareness & 13.46 & 13.38 & 3.86 & 0.062 & 0.239 \\
\hline Inter Personal Awareness & 13.42 & 14.10 & 3.55 & -0.574 & 0.297 \\
\hline Intra Personal Management & 14.23 & 14.45 & 3.79 & -0.174 & 0.245 \\
\hline Inter Personal Management & 14.26 & 14.25 & 5.70 & 0.005 & 0.244 \\
\hline
\end{tabular}

From the table: 4 it is seen that the distribution of Emotional Intelligence scores of boys secondary level students is negatively skewed, scores are massed at the high and of the scale spread out more gradually towards the left. In this distribution Mean, Median and SD is 55.58, 16.08 and 13.46 respectively. The value of kurtosis Emotional Intelligence of Boys is 0.311 , which is greater than 0.263 and it indicates that the distribution is platokurtic.

In the distribution of Emotional Intelligence (Intra Personal Awareness) Mean, Median and SD scores of Boys are 13.46, 13.38 and 3.86respectively. The computed value of kurtosis is 0.239 , which $\mathrm{s}$ less than 0.263 ; it indicates that the distribution of the scores is leptokurtic. The distribution is positively skewed or we can say skewed to the right, when scores are massed at the left end of the scale and are spread out gradually towards the right end.

The distribution Emotional Intelligence (Inter Personal Awareness), the scores of Boys emotional intelligence of secondary level is negatively skewed or to the left. The computed value of kurtosis is 0.297 which is greater than 0.263 , It shows the distribution of the scores is platokurtic. The Mean Median and SD score is 13.42, 14.10 and 3.55 respectively.

The distribution of Emotional Intelligence (Intra Personal Management) the scores of Boys of secondary level is negatively skewed or the left, i.e. scores are massed at the high end of the scale and spread out more gradually towards the low. The computed value of kurtosis is 
0.245 which is less that 0.263 ; it indicates that the distribution is leptokurtic. The Mean Median and SD scores are 14.23, 14.45 and 3.79 respectively.

The distribution of Emotional Intelligence for Boys of secondary standard (Inter personal Management), is positively skewed or skewed to the right, i.e. scores are massed at the low end of the scale and are spread out more gradually towards the high or the right end. 14.26, 14.25 and 5.70 is the score of Mean, Median and SD of the distribution. The computed value of Kurtosis is 0.244 which is less than 0.263 ; it shows the distribution of the score is leptokurtic.

In order to determine the Emotional Intelligence of Girls', the researcher administered the EII on 78 Girls' and computed Mean, Median, SD, Skewness and Kurtosis.

Table 5 Level of Emotional Intelligence of Girls

\begin{tabular}{|l|c|c|c|c|c|}
\hline \multicolumn{1}{|c|}{ Areas } & Mean & Median & SD & Sk & Ku \\
\hline $\begin{array}{l}\text { Emotional Intelligence Inventory (Full } \\
\text { scale) }\end{array}$ & 60.84 & 60.80 & 9.83 & 0.012 & 0.247 \\
\hline Intra Personal Awareness & 14.96 & 14.78 & 2.86 & 0.188 & 0.285 \\
\hline Inter Personal Awareness & 15.65 & 15.44 & 3.20 & 0.196 & 0.434 \\
\hline Intra Personal Management & 15.15 & 15.45 & 3.32 & -0.271 & 0.285 \\
\hline Inter Personal Management & 15.46 & 15.39 & 4.48 & 0.046 & 0.674 \\
\hline
\end{tabular}

From the Table:5, it is seen that the distribution of Emotional Intelligence scores of Girls of secondary school of Kamrup (M) district is positively skewed or skewed to the right, i.e. scores are massed at the lower end of the scale and are spread out more gradually towards the high end. The value of kurtosis is 0.247 which is less than 0.263 ; it indicates that the distribution is leptokurtic. The Mean, Median and SD are 60.84, 60.80, and 9.83 respectively.

In the distribution of Emotional Intelligence (Intra personal awareness) scores of Girls is positively skewed or to the right, as scores are massed at the left end of the scale and are spread out gradually toward the right end. The computed value of kurtosis is 0.285 , greater than 0,263; it indicates that distribution is platykurtic. The Mean, Median, SD is 14.96, 14.78, 2.86 respectively.

The distributions of emotional intelligence (Inter personal awareness) scores of the secondary level girl students are positively skewed or to the right and scores are massed at the left end of the scale and are spread out gradually towards the right end. The Mean, Median and SD scores are $15.65,15.44$, and 3.20 respectively. The computed value of kurtosis is 0.434 , greater than 0.263 , it means the, score distribution is platykurtic.

The distribution of emotional (Intra personal management) the Mean, Median and SD scores are 15.15, 15.45, 3.32 respectively. The computed value of kurtosis is 0.285 , greater than 0.263 , it means the, score distribution is platykurtic. The scores of the distribution is negatively skewed or to the left, when scores are massed at the right end of the scale and are spread out gradually towards the left end.

The distribution of emotional intelligence (Inter Personal Management) the scores are positively skewed or skewed to the right or high end. The computed value of platykurtic is 0.674 which is greater than 0.263 , so it indicates that the distribution of scores is platykurtic. The Mean, Median and SD are 15.46, 15.39, and 4.48 respectively. 
A Study on Emotional Intelligence of Secondary School Students with Special Reference to Kamrup (M) District of Assam

\section{Objective-2}

Table 6 Result of 't-test' of emotional intelligence score of secondary school students with respect to their gender.

\begin{tabular}{|l|c|c|c|c|c|l|}
\hline \multicolumn{1}{|c|}{ Groups } & N & Mean & SD & t-value & df & Significant Level \\
\hline Boys & 78 & 55.58 & 13.46 & \multirow{2}{*}{2.79} & 154 & $\begin{array}{l}\text { Significant At } 0.05 \\
\text { Level }\end{array}$ \\
\hline Girls & 78 & 60.84 & 9.83 & & & \\
\hline
\end{tabular}

Obtained $\mathrm{t}$ value is higher than both the tabulated value of 1.96 and 2.58 at 0.05 and 0.01 levels of significance. Hence, the null hypothesis is rejected. It indicates there is a significant difference between boys and girls of secondary schools as far as their Emotional Intelligence is concerned.

\section{FINDIGS AND DISCUSSION}

Main findings of the study are as follows-

- Emotional Intelligence of most of the secondary school students is average with $44.25 \%$.

- In case of the level of emotional intelligence, the level of Emotional Intelligence of girl's is more than the level of Emotional Intelligence of boys. As a whole in full scale inventory it is seen that Mean, Median, SD, SK, Ku of Boys are 55.58, 60.08, 13.46, 1.00 and 0.311 respectively where in case of girls Mean, Median, SD, SK, Ku are $60.84,60.80,9.83,0.012$ and 0.247 respectively.

- In every area of Emotional Intelligence (Intra Personal Awareness, Inter Personal Awareness, Intra Personal Management, Inter Personal Management) Girls scores are more than the boys of secondary level of Kamrup(M) district. The score of Girls in regard to Intra personal Awareness are Mean=14.96, Median=14.78, $\mathrm{SD}=2.86, \mathrm{SK}=$ 0.188 and $\mathrm{Ku}=0.285$ where Boys $\mathrm{Mean}=13.46$, Median=13.38, $\mathrm{SD}=3.86, \mathrm{SK}=$ $0.062, \mathrm{Ku}=0.239$. In regards to Inter Personal Awareness Mean, Median, SD, SK, $\mathrm{Ku}$ of Girls are 15.65, 15.44, 3.20, 0.196 and 0.434 respectively. Boys Mean, Median, SD, $\mathrm{SK}, \mathrm{Ku}$ are $13.42,14.10,3.55,-0.574$ and 0.297 respectively. In the area of Intra Personal Management Girls score are Mean=15.15, Median=15.45, $\mathrm{SD}=3.32, \mathrm{SK}=-$ $0.271, \mathrm{Ku}=0.285$ and Boys Mean=14.23, Median=14.45, $\mathrm{SD}=3.79, \mathrm{SK}=-0.174$, $\mathrm{Ku}=0.245$. In the area of Inter Personal Management Mean, Median, SD, SK, Ku of Girls are 15.46, 15.39, 4.48, 0.046 and 0.674 respectively, here the score of Mean, Median, SD, SK, Ku of Boys are 14.26, 14.25, 5.70, 0.005 and 0.244 respectively.

- The result of "t- test" of Emotional Intelligence score of Secondary School Students with respect to their gender is 2.79 which is higher than both the tabulated value of 1.96 and 2.58 at 0.05 and 0.01 levels of significance.

- From the study it is found that null hypothesis is rejected and in indicates significant difference between Boys and Girls of Secondary Schools as far as their Emotional Intelligence is concerned.

\section{CONCLUSION}

In conclusion, it is said that Emotional Intelligence is recognized as the key factor of individual's success. In everyone's life everyone faces many problems in their day to day life, in student's life also they have to tackle with many problems, it may be social, emotional, personal or economical etc. So, Emotional Intelligence always helps a person to deal with their problems and makes their life smooth. It always provides us skills to balance our life by 
managing stress depression or different kinds of problems. It is a concept, which is very practical in nature and yes, seems to be very effective and essential for the development of human life.

\section{REFERENCES}

[1] Chawla H., Pannu R. and Bhullar G.S. (2011): General Intelligence, Emotional Intelligence and Scholastic achievement of commerce 10+2 grade students. Journal of community Guidance \& Research, 20 (s): 476-782

[2] Goleman D. (1995): Emotional Intelligence. New York: Bantom Books.

[3] Krishnamurthy, M \& Varalakshmi, S, "Emotional Intelligence- A study with special reference to the employees of Salalah college of technology", International Journal of Research in commerce and Management, vol. No. 2, Issue 1 Pg-23-34, ISSN 0976-2183, 2011

[4] Parker, J.D.A., summer feldt, L.J., and others (2004): Emotional Intelligence and academic success: Examining the transition from high school to university. Personality and Individual Deterrence's, 36, Pg163-172

[5] Petrides, K.V., Frederickson, N., and Furnham, A. (2004): The role of trait emotional intelligence in academic performance and deviant behavior of school. Personality and Individual Difference, 36, pg-277-293

[6] Rani R. (2011): Emotional Intelligence and academic achievement of visual $>$ disabled students in integrated and segregated schools. Disabilities and Impairments, 25 (1-2): 44-50

[7] Sikhwari T.D. (2014): A study of the Relationship between Motivation Self-concept and Academic Achievement of students at a University of Limpopo Province, South Africa. International Journal of Educational Science 6(1) 10-25

[8] Subramanyam K. and Rao K.S. (2008): Academic Achievement and Emotional Intelligence of secondary school children. Journal of community Guidance \& Research, (25): 224-228 